\title{
Leisure Sport Industry and Economic Development
}

\author{
Deng-Minwei
}

( Department of Jinan Sport University, Guangzhou 510632)

Key words: leisure sport; leisure sport industry; economy. CLC: G80-05 Document Code: A

\begin{abstract}
. leisure sport industry is the tertiary industry, whose economic features are indivisibility between production and consumption and relatively large elasticity of substitution of leisure sport products' factors of production; Leisure sport products have quality of final product and economy is the foundation of development of leisure sport industry. The development of the economy promotes progress of leisure body building entertainment industry. Leisure sport improves industrial structure, expands employment space, impels progress of economy, meets people's sports demands, and facilitates development of leisure sport industry. For developing leisure sport industry, it is required to establish the corresponding administrative organization, perfect the rules and regulations, develop the market of leisure sport industry and attach great importance to personnel training.

With the constant development of our market economy and the increase of leisure time, physical culture has started to enter into people's daily life in our country. With the increasingly enhancement of people's living standard, people's consumption concept and life style has also changed. The concepts of spending for health and paying for happiness have reached common ground. And leisure sport has started to enter into people's lives. Leisure sport has attracted social public due to its particular charm. Not only does it have competitive sports' happiness of overcoming difficulties and defeating opponents, but also it has the effects of strengthening one's physique and promoting health; not only does it have expectation to the unpredictability of competitive sports' results, but also it has casual leisure from disregarding success or failure in health sports; not only does it possess sense of achievement in defeating nature and overwhelming personal success, but also it owns the life confidence of remolding oneself and healthy personality. Leisure sport activity can rich people's spare culture lives, ameliorate people's life style, shorten distance between people and strengthen one's physique, and it is representation of sports' nature function. Therefore, leisure sport can be developed rapidly. And leisure sport industry that relates to leisure sport has also got unprecedented prosperity. The large leisure sport consumption market has produced unlimited business opportunity and brought huge investment space to investors.
\end{abstract}

\section{Concepts of leisure sport and leisure sport industry}

\section{Concept of leisure sport}

Leisure sport is separated from leisure (healthy) activity. Before that, leisure sport is only considered as a sport form that clings to other sport forms, integrates with the whole sport concept, or is blended into the category of national sport, or others. Up to now, leisure sport still cannot get its due position in traditional sport. At the early stage of 1980s, Kelly, the American leisure sociologist, said: "leisure sport enables participants to freely choose and obtain essential satisfaction.” “Japan Leisure Sport Development Association” recognized by lifelong PE class of Japan MEXT defined leisure sport in "mission of association establishment" as "leisure sport does not refer to sport items, such as golf, motor, racing, and other leisure

items, while no matter what sport item it is, only if it is figured as a leisure sport and people could achieve the purposes of happy body and mind, cheer, optimistic mood and fatigue relieve, it can be called leisure sport." Our researchers believe that "leisure sport is a social culture activity which is introduced by inner incentive, for the purposes of relieving from external environment pressure, taking a break and recreation in a sport mode that you like it and you can naturally feel value in it, cultivates physical ability, intelligence and sport ability that have nothing to do with economic benefits, and people can freely participate sport activity and exert sport talents”. Qu 
Zonghu considers leisure sport as a condition sport. Above all, it should be limited by time condition. If there is no spare time, there will be no leisure sport. Besides, it should be constrained by economic condition. If there is no economic condition as foundation, people would not take part in sport activity even if they have leisure time. Thirdly, it should be limited by people's new thoughts and new concepts. If people do not build corresponding leisure sport development concept, leisure sport cannot stand out general sport form.

In conclusion, leisure sport refers to a social activity which enables people to reach the purpose of delighting body and mind, cultivating their minds, actualizing them and perfecting themselves by basic methods of body practice and sports to participate willingly and choose freely in their governable time.

Definition of leisure sport industry

Leisure sport industry refers to the industry domains that closely relate to the leisure sports provided by each department in the society. It includes all of the products and services concerning sport activities and the total operational activities relate to these products and services. Leisure sport industry mainly includes sport body building leisure industry, sport competition performance industry, sport agency consultation industry, sport training industry, sport product industry, sport lottery industry and sport tourism. As leisure sport, leisure sport industry also needs to take the sufficient leisure time as precondition, the rich social and personal material basis as condition, and the advanced life long sport concept as guarantee. Presently, leisure sport industry is gradually developing to the new industry, although it has not formed an individual leisure sport main industry and still clings to other sport industries, leisure activities, or group sport activities; it will undoubtedly drive the development of sport industry in the near future and guarantee the sustainable development of sport industry.

\section{Economic features of leisure sport industry}

Indivisibility of production and consumption

The indivisibility of production and consumption refers to indivisibility of products' production and consumption in time and space. The basic utilities of sport service products and production inputs are elevating people's function and mental level and realizing the "reproduction" ability to increase service products, which can be represented in meeting people's demands of dissipating fatigue, recovering energy and building a sound body. Its value in use is almost the same as eating and drinking each kind of tonic. Leisure sport product is hard to be stored, which can only be produced while consumed. For instance, the consumption of ball games and body building practice and other products cannot separate production and consumption. If both do not have identity in time and space, their values are hard to be realized. People's major purpose of physical training is to enhance health, and it is impossible to achieve purpose of building a sound body by watch TV or video instead of self physical training.

Satisfaction to people's high level requirements

People's demands are hierarchical. After the demands in low level are satisfied, they will produce desire for high level. Every level also includes requirements to different goods of the same demand level, and these demands are requirements with payment ability. If the income is limited and cannot meet requirements of high level, people will naturally purchase higher goods for self-demand with the increased income under control of consumption preference after the basic requirement is met, namely, with the increasing increase of per capita income level, the keystone of demands will also transfer to higher level with the change of concept. From the aspect of modern sport consumption level, people's consumption in sport product aspect is mainly for meeting the demands of high level.

Leisure sport products possess qualities of final products

On the one hand, Leisure sport products are products with labor service form. A large part of its value is constituted by labor consumption. Inputs, such as sport appliance, take up relatively smaller proportion in this industry, and consequently, it has the feature of small intermediate input. On the other hand, the proportion of leisure sport product that is considered as input for other industries is 
small. People generally consider the satisfaction to the demands of final consumption, so leisure sport product has the quality of final products.

\section{Relation between leisure sport industry and economy}

Economy is the foundation of leisure sport industry development

Economy is the requirement of leisure sport industry development. The economic guarantee is the precondition of sport investment and sport consumption. Sport investment and sport consumption are mainly limited by economic factors of social economic development level, resident per capital level and others. From the aspect of our present situation, due to the influence and limitation of economic level, investment conception, decision making and other factors, leisure sport industry still relies on national investment. From the aspect of consumption structure, although people's income level is elevated year after year, the general level and consumption structure of our country are still relatively low and irrational, and the investment and consumption of sport are still under the primary stage.

The economic level of our country constrains the scale and level of leisure sport industry. It mainly represents in aspects of small scale of leisure sport industry, low vigor, weak market competition and small scale. From the aspect of demand, the subject of market is not totally changed in the concept of consumers. The consuming ability and level is still relatively low and the consumption structure is irrational.

Impulse function of the development of leisure sport industry to economy

The development of leisure sport industry can improve industrial structure

Although the tertiary industry has got rapid development in this year, small whole scale, irrational structure, narrow domain and other predicament still exist. And it attaches great importance on restaurant, transportation, wholesale, retail and other traditional service industry, and finance, information, assurance, plan, consultant and other modern service industries are not so well developed. Leisure sport market lacks standardized administration, and the operation and management mechanism of sound circle development. Many residents have certain sport consumption concept, so they can promote the development of sport market if actively led. Although the development of leisure sport just started, it is an industry with strong relevance. It has closely reliance and relevance with other relevant industries. Accordingly, for one thing, the development of leisure sport industry can impulse the progress of business, manufacturing, transportation, catering, finance, assurance, education, health and other industries, and improve the industrial structure of the western region. For another, it can drive development of sport competition performance industry, sport agency consultation industry, sport training industry, sport product industry, sport lottery industry, sport tourism, etc.

Revenue enhancement and financial strength elevation

Revenue is the fund source of country and region for providing national defense, public security, public investment, social welfare and other "public products", and it is the basic condition for keeping the normal, steady and sustainable development of society. The revenue of leisure sport industry mainly comes from provider and consumer of leisure sport labor and leisure sport product, which mainly include two aspects. The first one is the sales tax and income tax of each leisure sport industry operating department, and the second one comes from the revenue of relevant industrial department.

\section{Development countermeasure to leisure sport industry}

Establish and perfect the administrative organization of leisure sport industry.

The leisure sport industry of our country is developed under the foundation of insufficient sport industry, and it naturally undertakes negative influence from many different aspects. The administrative department should recognize the development orientation of our leisure sport industry, accurately hold the practical development condition of leisure sport industry in our country, establish and perfect the administrative organization, and explore the operation mechanism of 
management of leisure sport industry in the development practice of leisure sport industry so as to adjust to the development demands of leisure sport industry.

Policy support. Leisure sport industry is a new industry, so our country should give policy support. For instance, it can encourage society to invest the operating activities of leisure sport programs by rational revenue policy, develop and introduce new sport service items, advisably derate all kinds of revenues to the new sport service programs and give them supports, and promote the rapid development of leisure sport and leisure sport industry.

Develop and establish leisure sport industry market. With the actualization of nationwide fitness plan and the successful conduction of the Olympic Games, the public sport and entertainment sport which give priority to body building and entertainment will get people's preference in the future. So we should seize the right development orientation of leisure sport industry, attach great importance to the cultivation and development of future market, grasp the good development opportunity and realize rapid development.

Establish and perfect rules and systems. Rules are the important guarantee of developing leisure sport industry, so the administrative department should establish and perfect rules of leisure sport industry as soon as possible, regulate market order and drive the development of leisure sport industry become scientization, standardization and institutionalization.

\section{Conclusion}

Although leisure sport industry got rapid development and active extension in the 1970s, due to the self particularity of leisure sport, it has not been regarded as industrial scale, namely, leisure sport industry is an immature industry that is under development. Even so, leisure sport industry represents its special advantages in adjusting industrial structure, enlarging employment, promoting national economic development and other aspects. Therefore, the development of leisure sport industry is an important approach of meeting people's increasingly enhanced sport and culture demands and promoting economic development.

\section{Reference}

[1] Qu Zonghu, Introduction of Sport Industry Study [M]. Beijing. Physical Education University Press, 2000.8,94.

[2] Liu Huimei, Brief Analysis on Market Prospect of Leisure Sport Industry of Our Country [J]. 2004.12 